Editorial

Editorial

Maria Cecília de Moura ${ }^{1}$ (1)

Desirée De Vit Begrow² (1)

Adriana Di Donato Chaves $^{3}$ (C)

Cíntia Alves Salgado Azoni ${ }^{4}$ (1)

\section{Fonoaudiologia, língua de sinais e bilinguismo para surdos}

\section{Language therapy, sign language and bilingualism for the deaf}

A Fonoaudiologia está historicamente ligada à surdez e à pessoa surda. Esta atuação se explica ao verificar-se a origem da profissão marcada pela imposição ao gerenciamento social que objetivava unificar as formas de expressão utilizadas no Brasil ${ }^{(1)}$. Assim, fazer com que aquele que não ouvia ou ouvia mal pudesse se adequar às normas da língua, se configurou como campo ideal de trabalho da Fonoaudiologia. As ações iniciais, no século XX, de cunho marcadamente oralista, se estendiam da clínica à escola e os professores eram ensinados a atuar com alunos surdos e todo esforço era feito para que ele pudesse se adequar às normas da língua oral num trabalho clínico intensivo.

Este cenário pôde ser encontrado até a década de 1980, quando pesquisadores brasileiros, entre eles Yoshioka et al. ${ }^{(2)}$ e Ciccone ${ }^{(3)}$, fundamentalmente embasados pelos trabalhos publicados nos Estados Unidos, trouxeram uma filosofia nova no trabalho com surdos, chamada Comunicação Total. Tal filosofia introduz o uso de signos linguísticos sinalizados tanto da língua de sinais (LS) do Brasil, como dos Estados Unidos. Inicialmente, indicada para os surdos com insucesso na oralização, a Comunicação Total passa a ser adotada por pessoas com diferentes níveis e tipos de perdas auditivas ${ }^{(4)}$.

Em 1990, voltou-se o foco para o bilinguismo para surdos. Pesquisadores fonoaudiólogos passaram a utilizar intervenções baseadas numa modalidade gestual-visual, embasados nos princípios de direitos das minorias linguísticas, contemplando as línguas de $\operatorname{sinais}^{(5,6)}$.

No decorrer do século XXI, o que passou a ser chamado de Fonoaudiologia Bilíngue para Surdos tomou corpo com a realização de pesquisas e a consequente ampliação da produção científica voltada para a área ${ }^{(7-12)}$.

A Sociedade Brasileira de Fonoaudiologia (SBFa), instituição de reconhecimento internacional que tem como um dos objetivos divulgar e discutir a produção científica, aprovou em 2019 o Comitê de Língua de Sinais e Bilinguismo para Surdos alocado dentro do Departamento de Linguagem referendando-o em 2020.

Este comitê, conectado aos preceitos contemporâneos de inclusão e diversidade na comunicação, tem por meta a integração dos profissionais da Fonoaudiologia que atuam na área da linguagem relacionada às línguas de sinais, utilizadas por pessoas surdas ou ouvintes. Tendo esta concepção, se aprofunda o conhecimento da área da comunicação humana, para a realização de novas pesquisas que embasem a utilização da modalidade gestual-visual no trabalho fonoaudiológico. Ademais, busca promover a discussão e colaborar na construção e aprimoramento de políticas públicas relacionadas à comunidade surda sinalizadora ${ }^{(13,14)}$.

Ao mesmo tempo, são alçados novos objetivos para a Fonoaudiologia 4.0, tais como, ampliar o conhecimento dos profissionais sobre a atuação com surdos a partir da Fonoaudiologia Bilíngue Libras/Português; delinear de forma clara o campo de atuação do fonoaudiólogo que trabalha com língua de sinais; propiciar a elaboração de estratégias de intervenção em que o fonoaudiólogo, utilizando a língua de sinais, possa planejar e realizar seu trabalho de forma a atingir os objetivos pretendidos; discutir políticas públicas que levem em consideração aspectos relacionados a intérpretes de língua de sinais, questões técnicas de acessibilidade comunicacional, inclusão digital; propor espaços de discussão em âmbitos municipais, estaduais e federais quanto a inserção e o papel do Fonoaudiólogo no trabalho com indivíduos surdos/deficientes auditivos e a LS; incentivar a produção científica em Fonoaudiologia e LS.

\footnotetext{
${ }^{1}$ Departamento de Teorias e Métodos da Fisioterapia e Fonoaudiologia, Pontifícia Universidade Católica de São Paulo - PUC - São Paulo (SP), Brasil.

${ }^{2}$ Departamento de Fonoaudiologia, Universidade Federal da Bahia - UFBA - Salvador (BA), Brasil.

${ }^{3}$ Departamento de Fonoaudiologia, Universidade Federal de Pernambuco - UFPE - Recife (PE), Brasil.

${ }^{4}$ Departamento de Fonoaudiologia, Universidade Federal do Rio Grande do Norte - UFRN - Natal (RN), Brasil.
}

Fonte de financiamento: nada a declarar.

Conflito de interesses: nada a declarar.
Av. Reitor Miguel Calmon, s/n, Vale do Canela, Salvador (BA), Brasil, CEP: 40110-100.

E-mail: desiree@ufba.br 
O Comitê de Língua de Sinais e Bilinguismo para Surdos da SBFa ao consolidar o espaço científico para os fonoaudiólogos, alcança outros públicos, tais como as próprias pessoas surdas/ deficientes auditivas, tradutores e intérpretes de LS, educadores e outros usuários ouvintes (familiares, amigos etc.). Três são as dimensões da língua de sinais na Fonoaudiologia: (1) aquisição típica da LS; (2) bilinguismo educacional para aprendizes surdos e (3) atipias em LS.

A primeira dimensão contempla a aquisição típica da LS como primeira língua (L1), atuando na prevenção das alterações de linguagem na infância em LS e na orientação e acompanhamento aos familiares. A identificação e a intervenção precoce são de extrema importância. O fonoaudiólogo atua no desenvolvimento de estratégias de intervenção para que, na ocorrência de um distúrbio na criança surda, este possa ser minimizado ou completamente superado eliminado ${ }^{(15,16)}$.

A segunda dimensão propõe a atuação em âmbito educacional de forma a contribuir para o letramento na primeira língua (L1) e segunda língua (L2), facilitando o contato da criança surda com a Língua Portuguesa como L2, sempre mediada pela LS. Frente às características de inovação e experimentação científica dos espaços de aprendizagem, diversas clínicas-escola de Fonoaudiologia no Brasil, ao longo das últimas décadas, vêm desenvolvendo atividades de ensino, pesquisa e extensão voltadas ao bilinguismo educacional para aprendizes surdos, como é o caso da PUC/SP, Santa Casa de Misericórdia/SP, UFPE, UFBA, dentre outras.

Por fim, a terceira dimensão, refere-se à atuação do fonoaudiólogo frente às atipias em LS, na prevenção e intervenção nos diferentes ciclos de vida.

O termo língua de sinais atípica pode ser usado para qualquer manifestação de desordem da comunicação expressa nas línguas de sinais, de acordo com as definições propostas por Andrade (1996), aplicáveis a desordens do desenvolvimento, como as geradas pelo atraso na aquisição ou a desordens adquiridas, que podem ser resultado de um déficit primário (uma doença que não é consequência de outra) ou secundário (ocorrendo como consequência de outra patologia) $)^{(17: 749)}$.

Ao atuar com competência bilíngue frente às pessoas surdas, a intervenção fonoaudiológica obedecerá “[...] aos mesmos princípios conceituais que dão suporte à prática clínica na reabilitação dos distúrbios de linguagem nas línguas orais"(17).

Desta forma se evidencia um novo olhar da fonoaudiologia ${ }^{(18)}$ destinado à pessoa surda em variados momentos e situações e nos diferentes ciclos de vida e essa atuação pode mostrar-se fundamental, uma vez que respeita a heterogeneidade do surdo e sua singularidade linguística.

\section{REFERÊNCIAS}

1. Berberian AP. Fonoaudiologia e educação: um encontro histórico. São Paulo: Plexus; 1995.

2. Yoshioka MCCP, Spinelli M, Teixeira VRV, Moura MC. Utilização de comunicação total em sujeitos com deficiência auditiva severa. In: Paiva AF, Spinelli M, Vieira S, editores. Distúrbios da comunicação: estudos interdisciplinares. São Paulo: Cortez/Autores Associados; 1981.p. 147-88. (Coleção Educação Contemporânea. Série: Educação Especial).

3. Ciccone M. Comunicação total. Rio de Janeiro: Cultura Médica; 1990.

4. Moura MCO. Surdo: caminhos para uma nova identidade. Rio de Janeiro: Revinter; 2000
5. Guarinelo AC, Claudio DB, Festa PSV. A produção do conhecimento em Fonoaudiologia, Educação e Psicologia acerca da linguagem e da surdez: análise de periódicos. Cienc Cult. 2012;45:115-32.

6. Moura MC. Libras e Fonoaudiologia: territórios a serem compartilhados. In: Araújo AN, Queiroga B, Lucena J, Studart L, editores. Questões contemporâneas da clínica fonoaudiológica. São José dos Campos: Editora Pulso; 2018. p. 215-25.

7. Begrow DV. A constituição da identidade do sujeito surdo a partir da perspectiva sócio-histórico cultural: uma reflexão. In: Santos MC, Gonçalves IMC, Duboc MJ, Ribeiro SL, Castro ASA, editores. Educação inclusiva em foco. Feira de Santana: Universidade Estadual de Feira de Santana; 2006. p. 109-1026.

8. Di Donato A, Oliveira SMD. Libras I. In: Faria EMB, Cavalcante MCB, editores. Língua portuguesa e Libras: teorias e práticas. 1. ed. João Pessoa: Editora Universitária da UFPB; 2010, p. 155-97.

9. Cruz CR, Pizzio AL, Quadros RM. Avaliação da discriminação fonêmica do Português Brasileiro e da Língua de Sinais Brasileira em crianças ouvintes bilíngues bimodais e em crianças surdas usuárias de implante coclear. Rev ABRALIN. 2015;14(1):407-30. http://dx.doi.org/10.5380/ rabl.v14i1.42824.

10. Cripps JH, Cooper SB, Supalla SJ, Evitts PM. Meeting the needs of signers in the field of speech and language pathology, some considerations for action. Comm Disord Q. 2015;37(2):108-16. http://dx.doi. org/10.1177/1525740115576955.

11. Nascimento V, Moura MC. Habilitação, reabilitação e inclusão: o que os sujeitos surdos pensam do trabalho fonoaudiológico? Rev Cienc Hum. 2018;52:1-19. https://doi.org/10.5007/2178-4582.2018.e49807.

12. Chaves ADD. Ações propositivas para o aperfeiçoamento de produções escritas por aprendizes surdos bilíngues. In: Faria BEM, Melo LGD, Cavalcante MB, Fernandes TA, editores. Letramentos e inclusão - PNAIC Paraíba. 1. ed. João Pessoa: UFPB; 2014. p. 63-84. (v. 1).

13. Alves LF, Leão MF, Agapito FM. Políticas públicas voltadas para a inclusão social de surdos. Rev Destaques Acadêmicos. 2017;9(2):149-62. http:// dx.doi.org/10.22410/issn.2176-3070.v9i2a2017.1399.

14. Vianna NG. Ruídos e silêncios: uma análise genealógica sobre a surdez na política de saúde brasileira [tese]. Campinas: Faculdade de Ciências Médicas, Universidade Estadual de Campinas; 2018 [citado em 2020 Set 22]. Disponível em: http://www.repositorio.unicamp.br/handle/REPOSIP/334621

15. Lichtig I, Barbosa FV. Abordagem bilíngue na terapia fonoaudiológica de surdos. In: Fernandes FDM, Mendes BCA, Navas ALPGP, editores. Tratado de Fonoaudiologia. 2. ed. São Paulo: Roca; 2009. p. 210-9. (v. 1).

16. Lichtig I, Barbosa FV, Moura GM. Educação e Surdez. In: Bento RF, Lima J, Penna LR, Koji TR, Goffi-Gomez MVS, Lima DVSP, Brito NR, editores. Tratado de implante coclear e próteses auditivas implantáveis. 1. ed. Rio de Janeiro: Thieme; 2014. p. 453-7. (v. 1).

17. Barbosa FV. A clínica fonoaudiológica bilíngue e a escola de surdos na identificação da língua de sinais atípica. Educ Real. 2016;41(3):731-54. http://dx.doi.org/10.1590/2175-623661121.

18. Moura MC, Begrow DDV, Di Donato A. Língua de sinais e fonoaudiologia bilíngue na atuação com o surdo em tempos de COVID-19. In: Azoni CAS, Lira JO, editores. Estratégias e orientação em linguagem: um guia em tempos de COVID-19 [Internet]. São Paulo: Sociedade Brasileira de Fonoaudiologia. p. 70-8 [citado em 2020 Set 22]. Disponível em: https:// lp.sbfa.org.br/guia/

\section{Contribuição dos autores}

MCM participou da idealização do estudo e elaboração e redação do artigo, DDVB participou da idealização do estudo e elaboração e redação do artigo; ADDC participou da idealização do estudo e elaboração e redação do artigo, CASA participou da idealização do estudo e elaboração e redação do artigo. 